Gaerner, H. J., Fischer, E. \& Hoss, J. (1989) Side-efiects of clozapine. Psychopharmacology, 99 (suppl.), S97-S100.

Karet, F. E., Dickerson, J. E. C., Brown, J., et al (1993) Bovril and moclobemide: a novel therapeutic strategy for autonomic failure. Lancet, 344, 1263-1265.

Naber, D., Holzbach, R., Perro, C., et al (1992) Clinical management of clozapine patients in relation to efficacy and side-effects. British Journal of Psychiatry, 160 (suppl. 17), 54-59.

D. TAYLOR

A. REVELEY

Maudsley Hospital

F. FaIVRE

London SE5 8 AZ

\section{Extreme suicidality following serotonin syndrome}

SIR: Dursun et al (1995) suggest that toxic serotonin syndrome (TSS) remains underreported and misdiagnosed. We wish to report extreme suicidality in a 17-year-old schoolgirl following the serotonin syndrome attributed to phenelzine, dothiepin and lithium which she had been receiving for a month for a treatment-resistant depression. During treatment, the patient developed the cardinal features of TSS: pyrexia, opisthonus, rigidity, restlessness and tremor (Sternbach, 1991) in the absence of recent treatment with neuroleptics or other aetiologies (Dursun et al, 1995). She recovered from TSS within two weeks of discontinuing all drugs and reverted back to her previous depressive stupor-requiring feeding via a nasogastric tube. She was subsequently transferred to our care and six weeks after TSS, clomipramine 25 increasing to $50 \mathrm{mg}$ was introduced. Within seven days of this, the patient developed an active suicidal drive. She made continuous efforts to lacerate herself and tried to ingest various objects, stating "I feel so awful I must die". Nursing staff had to remain hypervigilant as she would attempt to harm herself with any objects available such as light bulbs, pencils and glassware. The patient required continuous physical restraint from two nursing staff. Senior consultants with special expertise in mood disorders commented that the degree of suicidal drive, which lasted six weeks, was unprecedented in their experience. At six weeks the clomipramine was discontinued and the patient was treated with a repeat course of twelve ECT with a full recovery.

Although serotonergic drugs such as fluoxetine do not precipitate suicide (Beasley et al, 1991), it is suggested that paradoxical increases in suicidality may occur in some patients treated with drugs affecting serotonergic transmission (Mann \& Kapur, 1991). This case suggests that, following serotonin syndrome, increased sensitivity to even cautious reinstatement of a drug with serotonergic properties (clomipramine), may occur. Although the serotonin syndrome is rare, careful study of patients in the aftermath of TSS is indicated.

BeAsley, C. M., Dornseif, B. E., Bosomworth, J. C., et al (1991) Fluoxetine and suicide: a meta-analysis of controlled trials in the treatment of depression. British Medical Journal, 303, 685-692.

Dursun, S. M., Burke, J. G. \& Reveley, M. A. (1995) Toxic serotonin syndrome or extrapyramidal side-effects? (Letter). British Journal of Psychiatry, 166, 401-402.

MANN, J. J. \& KAPUR, S. (1991) The emergence of suicidal ideation and behaviour during antidepressant pharmacology. Archives of General Psychiatry, 48, 1027-1033.

STERNBACH, H. (1991) The serotonin syndrome. American Journal of Psychiatry, 148, 705-713.

M. A. Serfaty

S. MCCLUSKEY

D. ECCLESTON

Royal Victoria Infirmary

Queen Victoria Road

Newcastle upon Tyne NE1 4LP

\section{Brain damage and tardive dyskinesia}

SIR: I note with interest Pourcher et al (1995) suggest "occult acquired brain damage" as an aetiological factor in the development of neuroleptic-induced tardive dyskinesia (TD). The following two cases suggest a similar risk factor for SSRI-induced extrapyramidal side effects (EPS) and TD.

Case 1: A 32-year-old man presented with a depressive illness and was treated with paroxetine $20 \mathrm{mg} /$ day. At the age of 21 he had suffered a pontine haemorrhage due to undiagnosed hypertension that resulted in a left hemiplegia. He subsequently made a full neurological recovery. Within a few days of commencing paroxetine he developed left-sided dystonia of such severity that he was unable to walk. The paroxetine was discontinued and within a week his mobility had returned to baseline. He was then treated uneventfully with dothiepin.

Case 2: A 62-year old woman with Parkinson's disease and mild dementia presented with a depressive illness and was treated with paroxetine $20 \mathrm{mg} /$ day. Her anti-parkinsonian medications were unchanged. Over a three week period her mobility declined, due to increased rigidity and bradykinesia, from walking with the aid of one person to requiring three people to mobilise her. She also developed buccolingual masticatory TD. The paroxetine was discontinued and over the course of a month she regained her mobility. The TD however remains unchanged at four months. Her depression has been treated with trazadone to some effect. 
SSRIs have been described to produce EPS and TD (Arya, 1994; Coulter \& Pillans, 1995). If brain damage proves to be a common factor it might be as well to bear this in mind when prescribing SSRIs.

ARYA, D. K. (1994) Extrapyramidal symptoms with selective serotonin uptake inhibitors. British Journal of Psychiatry, 165, 728-733.

Coulter, M. \& Plllans, P. I. (1995) Fluoxetine and extrapyramidal side effects. American Journal of Psychiatry, 152, 122-125.

Pourchier, E., BARUCH, P., BOUCHARD, R. H., et al (1995)

Neuroleptic associated tardive dyskinesias in young people with psychoses. British Journal of Psychiatry, 166, 768-772.

Northern General Hospital

A. Al-Adwan Sheffield S5 7AU

\section{Psychosurgery for obsessional disorder}

StR: The reviews by Piccinelli et al (1995) and James \& Blackburn (1995) summarise the current state of knowledge of the outcome of treatment of obsessional disorder by pharmacological and cognitive therapeutic methods. The third major therapeutic approach, not mentioned in the studies, is psychosurgery.

We should like to draw attention to the review of psychosurgery in obsessional disorder (Mindus \& Jenike, 1992). A further important outcome study, conducted from one centre, is provided by Hay et al (1992).

Both papers indicate that psychosurgery, when conducted by present-day stereotactic techniques, retains an important role in the management of severe obsessional disorder resistant to other treatment. It is important to note that the cingulate gyrus lesion does not appear to have advantage over the techniques based on lesion in the fronto-thalamic radiation.

In Britain the procedure based on radioactive induced lesion, known as subcaudate tractotomy is predominant because of the use of this technique at the major national centre. We have adhered to a simpler and more limited approach by a circumscribed stereotactically placed lesion, $9 \mathrm{~mm}$ in diameter, in the fronto-thalamic radiation. An outcome study of our series does not prompt us to abandon the technique (Hay et al, 1993).

Sometimes there seems to be an impression that the Mental Health Commission has virtually banned psychosurgery. This is not the case, although rigorous standards are laid down. In the middle decades of this century vociferous denigration of somatic treatment for psychiatric disorder led to the widespread abandonment of psycho- surgery. Today the ethics should be questioned of withholding information concerning the existence of treatment which has been shown to offer some chance of relief from suffering. Our survey of psychiatric opinion (Snaith et al, 1984) which was undertaken prior to the establishment of the Yorkshire Regional Psychosurgery Service, confirmed that there was a requirement for the service not only for obsessional disorder but also for intractable depressive disorders, and a preference for the regional establishment of such a service.
Hay, P., Sachiev, P., Cumming, S., et al (1993) Treatment of obsessive-compulsive disorder by psychosurgery. Acta Psychatrica Scandinavica, 87, 197-207.
JAMES, I. A. \& BlaCkBURN, I. M. (1995) Cognitive therapy with obsessive-compulsive disorder. British Journal of Psychiatry. 166, 444-450.
Mindus, P. \& JeNIKE, M. A. (1992) Neurosurgical treatment of malignant obsessive-compulsive disorder. Psychiatric Clinics of North America, 15, 921-938.
Piccinelli, E., Pini, S., Bellantuono, C., et al (1995) Efficacy of drug treatment in obsessive-compulsive disorder. A meta- analytic review. British Journal of Psychiatry, 166, 424-443.
SNATth, R. P., Price, D. J. E. \& Wright, J. F. (1984) Psychiatrists' attitudes to psychosurgery. British Journal of Psychiatry, 144, 293-297.

St James's University Hospital

R. P. SNATth

Leeds LS9 $7 T F$

Pinderfields Hospital

D. J. E. PrICE

Wakefield, West Yorks

St James's University Hospital

J. MaRLOWE

Leeds LS9 7TF

\section{Treatment of obsessive-compulsive disorder}

SIR: Piccinelli et al (1995) seem to sideline exposure therapy given to many OCD sufferers in the UK by writing that although behaviour therapy has been reported to be more effective than pharmacological interventions and to provide long-term improvement with low relapse rate, in reality few patients actually undergo this treatment, either as a result of refusing to participate, high cost, andlor lack of qualified behavioural therapists (emphasis added).

The three points in italics deserve correction. First, in controlled studies, OCD patient refusal rates were in fact lower for exposure (behaviour) therapy than for clomipramine. Second, behaviour therapy costs less than medication in the long run as one-off exposure usually produces lasting improvement, whereas medication generally needs to be continued for years to avoid relapse. Finally, there 